Revista de Derecho

\title{
La justicia en un Estado plurinacional con garantismo penal: interculturalidad en ciernes
}

Justice with penal guarantees in a plurinational: interculturality in the making

\author{
Roberto Esteban Narváez Collaguazo \\ Antropólogo, Ecuador \\ Miembro de la Society for Anthropology of Lowlands South America \\ robertonarvaezc@gmail.com \\ ORCID: 0000-0003-4605-105X
}

DOI: https://doi.org/10.32719/26312484.2020.34.7

Fecha de recepción: 17 de octubre de 2019

Fecha de aceptación: 7 de enero de 2020

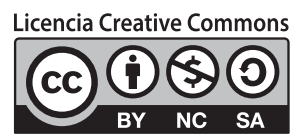




\section{RESUMEN}

Desde el año 2008, Ecuador introdujo en su Constitución los principios de plurinacionalidad e interculturalidad, reconociendo así la diversidad cultural presente en el país. Es justamente esa diversidad un reflejo de las distintas prácticas culturales enmarcadas en las tradiciones, las cuales aún no logran una comprensión integral desde la institucionalidad pública, especialmente en el ámbito judicial. El artículo desarrolla un análisis jurídico y antropológico alrededor de un estudio de caso, en torno a actividades de cacería tradicional relacionadas con la ritualidad, clasificadas de manera general bajo un tipo penal, en el que se discute la limitación del principio de interculturalidad y el procesamiento judicial que se realiza a la población indígena. De esta manera, se plantea la necesidad de la implementación de los principios constitucionales de plurinacionalidad e interculturalidad, en un espacio de diálogo equitativo que permita corregir esas limitaciones existentes, pero, sobre todo, una justicia que reconozca la necesidad de una ponderación adecuada durante el ejercicio del derecho penal bajo el principio de última ratio. PALABRAS ClAVE: diversidad cultural, tipo penal, interculturalidad, antropología jurídica, sistema de justicia, plurinacionalidad.

\section{ABSTRACT}

Since 2008, Ecuador introduced in its Constitution the principles of plurinationality and interculturality, as a way to recognize the cultural diversity present in the country. It is precisely this cultural diversity that maintains certain cultural practices framed in the traditions and linked to different forms of life, that still do not achieve an understanding from the public institutions and generate conflicts in the judicial field. The article develops a juridical and anthropological analysis, around a case study, about traditional ritual hunting activities, typifying a penal type, where the limitation of the principle of interculturality and the judicial processing that is done to indigenous population is discussed. In this way, the article seeks to show need for the implementation of the constitutional principles of plurinationality and interculturality in a space for equitable dialogue, where these limitations in the approach to cultural diversity could be assumed, but, above all, recognizing the need for an efficient weighting during the exercise of criminal law under the principle of ultima ratio.

KEYWORDs: cultural diversity, criminal type, interculturality, legal anthropology, justice system, plurinacionality. 


\section{INTRODUCCIÓN}

$\mathrm{E}$ nEcuador se reconocen los principios de "plurinacionalidad"e "interculturalidad" que reafirman el contexto de diversidad cultural del país. A pesar de ello, el reconocimiento a esa diversidad étnica y cultural encuentra un límite en lo jurídico, pues ciertos puntos de la legislación penal vigente generan un conflicto en el tratamiento de ciertos casos relacionados con prácticas tradicionales de ciertas colectividades culturales. Son conflictos en los que prevalece el ámbito normativo unicultural de la justicia ordinaria que defiende la consideración de igualdad de los miembros del Estado frente a prácticas culturales particulares.

La brecha en cuanto a reconocimiento de la diversidad cultural limita el acceso y la aplicación real de la justicia en un escenario de Estado multicultural ${ }^{2}$ y demuestra cómo los principios constitucionales de plurinacionalidad e interculturalidad tienen un vacío en su aplicación. Así, se presenta una relación de subordinación de los pueblos indígenas frente a un Estado hegemónico blanco-mestizo. ${ }^{3}$ Pero esta brecha, señalada anteriormente, no solo se presenta en el ejercicio del derecho, sino y sobre todo en la ausencia de discusiones dogmáticas en torno a la interculturalidad, reproduciendo el estudio del "ordenamiento jurídico para conocerlo, transmitir ese conocimiento, operarlo, optimizarlo, mejorarlo", ${ }^{4}$ y manteniendo una perspectiva que sigue alimentando a los actuales y futuros "operadores del derecho" en donde estas discusiones sobre interculturalidad tienen un limitado espacio de discusión, en el mejor de los casos. De esta manera planteamos trasladar el análisis desde el ámbito dogmático ${ }^{6}$ a través de una salida teórico metodológica que considera la investigación desde las ciencias sociales que aporten a los espacios de interpretación amplia, incorporando visiones que desde la interculturalidad permitan comprender la diversidad de concepciones y conductas en hechos fácticos concretos. ${ }^{7}$

1. Ecuador, Constitución de la República del Ecuador, Registro Oficial 449, 20 de octubre de 2008, art. 1.

2. Will Kymlicka, "Pensar el multiculturalismo", Íconos. Revista de Ciencias Sociales, n. 10 (abril 2001): 118-29. Kymlicka plantea que, en la esencia del multiculturalismo, el reconocimiento y respeto a la diversidad es la base que permite una relación igualitaria entre los actores.

3. Rodolfo Stavenhagen, "Conflictos étnicos y estado: Conclusiones de un análisis comparativo nacional", Estudios Sociológicos (El Colegio de México), XIX, n. ${ }^{\circ}$ (enero-abril 2001): 3-25.

4. Christian Courtis, "El juego de los juristas: Ensayo de caracterización de la investigación dogmática", en Observar la ley: Ensayos sobre metodologías de la investigación jurídica, ed. Christian Courtis y Manuel Atienza (Madrid: Trotta, 2006), 106.

5. Ibíd., 105.

6. Niklas Luhmann, Sistema jurídico y dogmática jurídica (Madrid: CEC, 1983).

7. Hesbert Benavente, La aplicación de la teoría del caso y la teoría del delito en el proceso penal acusatorio (Barcelona: Bosch, 2011); Christie Nils, Una sensata cantidad de delito (Buenos Aires: Ediciones del Puerto, 2004); Gonzalo Fernández, Bien jurídico y sistema del delito (Buenos Aires: Julio César, Editor, 2004). 
Así, en el ámbito de los procedimientos judiciales se requiere de una interpretación intercultural de los casos, ${ }^{8}$ y es allí que la capacidad para el entendimiento de los eventos y los hechos requiere un enfoque que integre varias disciplinas, desde la antropología $^{9}$ al derecho, siendo necesario una perspectiva intercultural en la institucionalidad judicial del Estado, con el fin de que se convierta en un "elemento de comunicabilidad entre la justicia indígena y la justicia estatal, entre el derecho propio de los pueblos y nacionalidades indígenas, y el derecho blanco-mestizo". ${ }^{10}$ Sobre todo, que rompa con el paradigma teórico jurídico liberal en donde el derecho se convierte en el instrumento de "regulación y normalización de las sociedades modernas", ${ }_{11}^{11}$ lenando todos los espacios de actividades y conductas, incluso de manera omnipresente; ${ }^{12}$ pero no solo eso, sino que la práctica jurídica se impone, y genera desarrolla un conflicto que solo puede ser abordado por el sistema judicial, ${ }^{13}$ rompiendo con principios y garantías, ${ }^{14} \mathrm{y}$ haciendo prevalecer el carácter punitivo del Estado. ${ }^{15}$

En la aplicación de la justicia en Ecuador se impone la justicia ordinaria positivis$\mathrm{ta}^{16}$ sin una legislación que reconozca un derecho basado en los usos y costumbres de los pueblos y nacionalidades indígenas. ${ }^{17}$ De esta manera las prácticas culturales y la

8. Roberto Narváez, “¿Un ejercicio de aplicación de la justicia intercultural? El caso waorani en la Amazonía Ecuatoriana", Revista Antropologías del Sur, año 3, n. 6 (2016): 163-79; Catherine Walsh, Interculturalidad, estado, sociedad. Luchas (de)coloniales de nuestra época (Quito: Universidad Andina Simón Bolívar / Abya-Yala, 2009); Álvaro Román, Interculturalidad, libertad y pena (Quito: Universidad Andina Simón Bolívar / Corporación Editora Nacional, 2015); Ramiro Ávila Santamaría, “¿Debe aprender el derecho penal estatal de la justicia indígena?", en Justicia indigena, plurinacionalidad e interculturalidad en Ecuador, ed. Boaventura de Sousa Santos y Agustín Grijalva (Quito: Abya-Yala, 2013), 279-304; Agustín Grijalva, "Conclusiones de todos los estudios: Experiencias diversas y convergentes de la justicia indígena en Ecuador", en Justicia indigena, plurinacionalidad e interculturalidad en Ecuador, ed. Boaventura de Sousa Santos y Agustín Grijalva (Quito: Abya-Yala, 2013), 551-78.

9. Christopher Loperena, Rosalva Aída Hernández Castillo y Mariana Mora, "Los retos del peritaje cultural: el antropólogo como perito en la defensa de los derechos indígenas", Desacatos; Tlalpan, n. 57 (2018): 8-19.

10. Luis Ávila, "Barreras ideológicas para la valoración judicial de los peritajes antropológicos", Revista Crítica Jurídica (Instituto de Ciencias Jurídicas de la Universidad Autónoma de México), 31 (2011): 15-37.

11. Michel Foucault, Vigilar y castigar (Buenos Aires: Siglo XXI, 1976), 170.

12. Michel Foucault, El pensamiento del afuera (Valencia: Pre-textos, 2000).

13. Pierre Bourdieu y Gunther Teubner, La fuerza del derecho (Bogotá: Uniandes, 2000).

14. Luigi Ferrajoli, Derecho y razón. Teoría del Garantismo Penal (Madrid: Trotta, 2005); Luigi Ferrajoli, Derechos y garantías: La ley del más débil (Madrid: Trotta, 2005).

15. Michel Foucault, La sociedad punitiva (Buenos Aires: Fondo de Cultura Económica, 2016); Foucault, El pensamiento; Foucault, Vigilar y castigar.

16. Ramiro Ávila Santamaría, La (in)justicia penal en la democracia constitucional de derechos: una mirada desde el garantismo penal (Quito: Ediciones Legales / Universidad Andina Simón Bolívar, 2013).

17. María Teresa Sierra, "Mujeres indígenas, justicia y derechos: los retos de una justicia intercultural", Íconos, n. ${ }^{\circ} 31$ (2008): 15-26; Boaventura de Sousa Santos y José Exeni Rodríguez, Justicia indígena, plurinacionalidad e interculturalidad en Bolivia, vol. 27 (La Paz: Abya-Yala / Fundación Rosa Luxemburgo, 2012). 
forma de vida tradicionales mantienen una condición de subordinación, ${ }^{18}$ en las que estas se encuentran invisibilizadas, ${ }^{19}$ no son reconocidas y ocupan un lugar secundario y al margen del Estado. ${ }^{20}$ Por lo antes expuesto se hace necesario un análisis para discutir la aplicación de la justicia ordinaria en hechos relacionados con acciones o conductas de miembros de pueblos y nacionalidades indígenas, identificando un conflicto por la práctica cultural y la administración judicial, ${ }^{21}$ planteando la necesidad de construcción de mecanismos de diálogo intercultural, ${ }^{22}$ útiles para el establecimiento de un Estado plural.

Con esta mirada, el objetivo del presente artículo es desarrollar un análisis jurídico y antropológico para identificar, en las actividades de cacería tradicional relacionadas con ritualidad, las limitaciones en el tipo penal en el procesamiento de casos judiciales bajo el tipo de delitos contra la flora y fauna. ${ }^{23}$ Se analizará con un estudio de caso, desarrollado a partir de una investigación etnográfica jurídica, relacionada con una pericia antropológica que fuera solicitada por la Fiscalía, dentro de un proceso judicial impulsado contra un poblador kichwa, en la que se puede analizar el choque entre la justicia ordinaria y las formas culturales particulares, evidenciando esta incertidumbre en el ejercicio de la interculturalidad.

\section{LA DIVERSIDAD CULTURAL, EL PUEBLO KICHWA EN LA AMAZONÍA ECUATORIANA}

El pueblo kichwa de la Amazonía ecuatoriana se encuentra distribuido en las provincias orientales de Orellana, Napo, y Pastaza, ${ }^{24}$ tiene su origen en procesos de composición étnica, producto de la relación entre las diferentes sociedades tribales que existían en la zona, de ascendencia saparo, omagua, tukano occidental y quijos, ${ }^{25}$ y cuya fusión consolidó varios grupos culturales que hasta ahora subsis-

18. Stavenhagen, "Conflictos étnicos y Estado".

19. Héctor Díaz Polanco, Elogio de la diversidad. Globalización, multiculturalismo y etnofagia (Ciudad de México: Siglo XXI, 2006).

20. Héctor Díaz Polanco, "Etnia, clase y cuestión nacional", Cuadernos Políticos, n. 30 (octubre-diciembre 1981): 53-65; Stavenhagen, "Conflictos étnicos y Estado"; Bartolomé Clavero, Geografía jurídica de América Latina. Pueblos indígenas y constituciones mestizas (Ciudad de México: Siglo XXI, 2008).

21. Narváez, ¿¿Un ejercicio...?”.

22. Walsh, Interculturalidad, Estado.

23. Ecuador, Código Orgánico Integral Penal, Registro Oficial Suplemento 180, 10 de febrero de 2014, art. 247.

24. Alba Moya, Ethnos. Atlas mitológico de los pueblos indígenas del Ecuador (Quito: Proyecto de Educación Bilingüe Intercultural / Ministerio de Educación y Cultura del Ecuador / GTZ, 1999).

25. Mary Elizabeth Reeve, Los quichuas del Curaray. El proceso de formación de la identidad (Quito: Banco Central del Ecuador / Abya-Yala, 1988); Norman E. Whitten, "La Amazonía actual en la base de los An- 
ten. ${ }^{26}$ Junto a los achuar, sapara, shiwiar, andwa y waorani constituye la diversidad étnica ${ }^{27}$ en esta región; habitan varios poblados tanto en las estribaciones como en los valles selváticos.

La familia lingüística de este grupo humano es el kichwa, ${ }^{28}$ hablado tanto en la sierra como en la Amazonía ecuatoriana. La conformación de estos grupos kichwa tuvo la mayor influencia del proceso de evangelización emprendido por la Iglesia en la época de la conquista, que los sometió a un cambio cultural, con la imposición de la lengua que prevalecía en los Andes, la reducción de los grupos familiares en asentamientos permanentes, y una diversidad de aspectos que modificaron sus culturas tradicionales. $^{29}$

\section{LA CACERÍA EN EL MARCO DE LA SUBSISTENCIA Y RITUALIDAD. EL CASO DE LA FIESTA DE SAN JOSÉ EN CURARAY}

La población kichwa amazónica maneja una economía de subsistencia, con actividades agrícolas domésticas, la cacería y recolección de productos de la selva, a la cual se encuentran ligados en el sentido espiritual, productivo y reproductivo, considerando que su relación directa es con la selva y sus recursos. ${ }^{30}$ Es tradicional que los ancianos y los padres sean actores importantes en el proceso de endoculturación, esto es, mantener viva la cultura.

La información etnográfica desarrollada a partir de una investigación cualitativa da cuenta que en el mes de marzo se celebran las fiestas de San José, patrono de la comunidad kichwa de San José de Curaray; ${ }^{31}$ esta es la festividad más grande que celebran

des: una confluencia étnica en la perspectiva ecológica, social e ideológica”, en Amazonía ecuatoriana. La otra cara del progreso (Quito: Abya-Yala, 1989), 13-60; John Edwin Hudelson, La cultura quichua de transición. Su expansión y desarrollo en el Alto Amazonas (Quito: Museo Antropológico del Banco Central / Abya-Yala, 1987).

26. Blanca Muratorio, Rucuyaya Alonso y la historia social y económica del Alto Napo, 1850-1950, vol. 68 (Quito: Abya-Yala, 1987).

27. Lilian Benítez y Alicia Garcés, Culturas ecuatorianas. Ayer y hoy (Quito: Abya-Yala, 1992).

28. El idioma de los kichwas amazónicos es el Runa Shimi (lengua de los hombres), que tiene diferentes variaciones o dialectos de acuerdo a la localización geográfica. Si bien la lengua kichwa se habla en un ámbito doméstico y familiar, la segunda lengua es el castellano, que permite las relaciones culturales, económicas, comerciales con la sociedad mestiza.

29. Hudelson, La cultura quichua de transición.

30. Reeve, Los quichuas.

31. Rueda (1995) define "yuxtaposición" cuando en el encuentro de dos religiones no se da una fusión entre ellas, sino que se unen las prácticas de dos "fe" diferentes. En este caso, en San José de Curaray existe 
los pobladores de la zona del Curaray y Villano. Se conoció que existen jornadas de preparación con al menos 8 días previos al festejo, donde el fiestero, que cumple las funciones similares al prioste, ${ }^{32}$ organiza a los pobladores en grupos que salen a la selva de cacería por un lapso de aproximadamente 8 días. En estas jornadas los cazadores obtienen diferentes especies silvestres a las cuales ahúman en ranchos en la selva, extraen las plumas y pieles, y confeccionan coronas y adornos que visten en el ingreso al pueblo. Por su parte, las mujeres recogen yuca de las chacras, confeccionan vasos y cuencos de cerámica, ${ }^{33}$ y preparan la chicha con la que reciben a los cazadores.

El día del santo, los cazadores entran a la plaza del pueblo cargando los animales cazados en las jornadas previas, cubiertos de los adornados que prepararon en la tarde y noche con las plumas y pieles de los animales, coronas y vestimentas. Desde la madrugada un pijuanero ${ }^{34} \mathrm{y}$ un tamborero ${ }^{35}$ empiezan a tocar sus instrumentos en la plaza. Al ingreso, los cazadores bailan en círculo alrededor de los músicos, integrándose las mujeres sirviendo chicha a los cazadores. Con los primeros bailes, los cazadores colocan los animales cazados en hojas colocadas sobre el piso y también las cuelgan en las casas, en un ejercicio de exhibición de las presas y, por tanto, de las capacidades del cazador como responsable de la provisión de alimentos para el núcleo familiar.

Por su parte, las mujeres van tomando las presas de cacería y las preparan en la cocina, y luego las sirven a los invitados acompañando con yuca y plátano verde cocinado. Los bailes se prolongan todo el día, con un espacio para una celebración religiosa en la iglesia del pueblo, y a lo que sigue una comida comunitaria. Durante los siguientes días, se integrarán elementos de la religión católica, en un recorrido de procesión por el pueblo con la Virgen y el patrono de la iglesia, que continúa con

una celebración a la selva bajo la nominación de un santo, sin perder, el sentido religioso y espiritual de los kichwa. Ver Marco Vinicio Rueda, "Encuentros del cristianismo español con las religiones precolombinas", en Cosmos, hombre y sacralidad, ed. Marco Vinicio Rueda y Segundo Moreno (Quito: Pontificia Universidad Católica del Ecuador, 1995), 267-304.

32. Prioste es el personaje encargado de organizar la celebración; su rol está envuelto de un poder alrededor de la fiesta, pues otorga los recursos y dirige la celebración, dando paso a una economía simbólica que vinculará a la acción con una importancia para las dinámicas internas comunitarias. El prioste tiene un alto valor simbólico pues permite la celebración, la ritualidad que sacraliza el tiempo y espacio vinculado con el personaje religioso "San José", pero que tiene tras de sí toda la representación de celebración a la selva y sus recursos.

33. Los cuencos son llamados purus, pilches o mocahuas, y se elaboran de arcilla; el arte consiste en elaborar cuencos muy delgados y delicados, los cuales son pintados con tinturas naturales y con una mezcla especial tendrán un brillo que los hará destacar; a continuación, serán sometidos a un proceso de cocción tras lo cual podrán ser utilizados (Diario de campo, 2017).

34. También denominado pifanero, interpreta un instrumento de viento similar a una flauta, el cual es elaborado de un bejuco al que se realizan tres agujeros que dan los tonos de la música (Diario de campo, 2017).

35. El personaje interpreta un pequeño tambor y junto al pifanero entonan un ritmo rápido que marca el paso de los danzantes y bailarines (Diario de campo, 2017). 
baile, comida y bebida, entre ella, vinillo, ${ }^{36}$ puro $^{37}$ y guaro. ${ }^{38} \mathrm{Al}$ final, como homenaje a la virgen se rompen los vasos, purus y vasijas elaborados para la fiesta.

La ritualidad forma parte de las prácticas tradicionales kichwa y se vincula con el uso del territorio y de sus recursos de manera tradicional (cacería, pesca, recolección y horticultura básica) y mantienen un contacto más directo con sus elementos espirituales. ${ }^{39}$ Esta forma de vida tradicional basada en la cacería, pesca y recolección es la que reafirma identitariamente a la población kichwa, integrándola a su territorio como un espacio de vida lleno de elementos naturales a través de los cuales se comunican con sus ancestros. ${ }^{40}$

Tanto el territorio como las tradiciones conjugan recursos naturales, espiritualidad y una población; la selva es la que garantiza la seguridad alimentaria de los grupos familiares y es en torno a este acto cotidiano que durante la celebración de San José se convierte en un espacio de celebración y de homenaje a esa selva proveedora de los recursos para la subsistencia. Así, la fiesta es un espacio ritual en el que se conjugan las tradiciones que expresan su forma de vida, la interrelación con la selva y sus recursos, y el agradecimiento por la abundancia, que es el eje central de la celebración.

\section{EL PROCESAMIENTO JUDICIAL BAJO EL TIPO DE DELITOS CONTRA LA FLORA Y FAUNA. ANÁLISIS DE CASO}

Según el parte n. ${ }^{\circ}$ UPMACP16029142 de 25 de marzo de 2017, en un operativo "anti delincuencial" ${ }^{41}$ fue detenido un vehículo de alquiler, en el que se encontró carne silvestre y dos tortugas terrestres de la especie Geochelone denticulata (tortugas motelo), trasladándolo al Puesto Fijo de Control Villano donde se convocó a personal

36. El vinillo es producto de la chicha fermentada y cernida, y queda el líquido con mayor nivel de alcohol (Diario de campo, 2017).

37. El puro es el aguardiente de la caña de azúcar, que se produce después de un proceso de cocción del jugo de la caña, cuyo vapor pasa por un alambique (Diario de campo, 2017).

38. Es el producto de la cocción del jugo de la caña de azúcar en su proceso de convertirlo en aguardiente, contiene gran cantidad de almidón y de azúcares (Diario de campo, 2017).

39. Andrea Madrid, "Entre killas y pifanos: desde la memoria social de los pueblos kichwas del Cuyabeno. Estudio de caso en la comunidad de Zancudo Cocha", Antropología. Cuadernos de Investigación 12 (2013); Reeve, Los quichuas; Whitten, "Amazonía actual”.

40. Roberto Narváez, "Estudio afectación a la seguridad y soberanía alimentaria de Sarayaku" (sin publicar, 2010).

41. Ecuador, Fiscalía de Pastaza, "Expediente fiscal”, Instrucción Fiscal 160101817030149, marzo de 2017. 
del Ministerio del Ambiente que presta servicio como Inspector Forestal y personal de la Unidad de Policía de Medio Ambiente (UPMA). Una vez que se identificaron los "elementos constitutivos (carne ahumada presumiblemente de especie sahino)" 42 y las tortugas, se procedió a detener tanto al conductor del vehículo como a quien lo había contratado.

Los partes policiales y las versiones de los policías señalan haberse seguido el procedimiento y respeto a los derechos de los detenidos; siendo este el traslado al Hospital del Puyo para una valoración médica antes de ponerlos a órdenes de la autoridad competente, el fiscal de turno, ingresando a continuación al Centro de Detención Provisional de Putuimi, pero nunca manteniendo una comunicación en idioma kichwa.

El procesado, originario de San José del Curaray, y de nombre K. Santi, vivía en la comunidad de Pakaychikta ${ }^{43}$ desde hace varios años, y retornaba de una invitación familiar a las fiestas de San José, con su familia nuclear compuesta por su esposa y tres hijos. Para el retorno su familia le habría entregado de regalo varias piezas de carne silvestre como una expresión de cariño, así como las dos tortugas, ${ }^{44}$ como un recuerdo de la selva.

El procesado señaló en su versión su desconocimiento acerca de la legislación que establece prohibición a la posesión y transporte de fauna silvestre, principalmente aquella que se encuentra en peligro de extinción, evidenciándose así un error de prohibición vencible, marcado por una percepción diferente enmarcada en contextos culturales diversos. La pericia antropológica expone segmentos de la entrevista realizada al procesado, quien se autoidentifica como kichwa:

Yo soy kichwa, nacido en Curaray, he vivido en el Tena, pero no sé que tener tortugas es delito y la carne no sé qué animal es. Estas cosas fueron regalos que me dieron en las fiestas que hubo el 21 de marzo de 2017 en Curaray, me detuvieron ayer a las $16 \mathrm{~h} 00 .^{45}$

La pericia también encuentra que en la cultura kichwa de la Amazonía, un regalo establece lazos de intercambio, consolidando así compromisos sociales, por lo que en la cultura kichwa el regalo se debe recibir, y, en el caso de la carne silvestre, consumirla como muestra de agradecimiento y de respeto. Por su parte, el regalo de animales vivos, como eran las tortugas, forma parte de las tradiciones, y es un ritual de traslado de recursos, buscando enriquecer la selva de la persona que recibe el regalo.

42. Ecuador, Fiscalía de Pastaza.

43. La comunidad se ubica en el sector de Ahuano, cerca de la ciudad del Tena.

44. Las tortugas habrían estado ya un buen tiempo como mascotas, lo que se evidenció por agujeros en los caparazones a los que son atadas finas cuerdas que impiden que los animales salgan del perímetro de las casas.

45. Ecuador, Fiscalía de Pastaza, "IF160101817030149”. 


\section{EL PROCESAMIENTO DIRECTO}

A continuación de la detención y el ingreso del parte policial a la fiscalía de turno -al tratarse de un delito ambiental contra la fauna y flora silvestre, un delito de acción pública-, la Fiscalía inició la fase de investigación previa, y requirió al juez de la Unidad Judicial Penal de Turno, la audiencia de calificación de flagrancia.

El 25 de marzo de 2017 se llevó a cabo la audiencia de calificación de flagrancia dentro de la causa $\mathrm{n}^{\circ}{ }^{\mathrm{T}}$ 16281-2017-00170 sustanciada mediante procedimiento directo, bajo el delito tipificado Delitos contra la flora y fauna silvestre, en el cual la autoridad judicial verifica la inmediatez temporal, inmediatez personal y flagrancia, y se convoca a la audiencia de procedimiento directo en fecha posterior (4 de abril de 2017). Así mismo, el fiscal requirió al juez la prisión preventiva como medida cautelar al no "existir ningún tipo de arraigo" ${ }^{46}$ del procesado, la que es ordenada "pudiendo apelar de no estar de acuerdo". ${ }^{47}$

El 28 de marzo de 2017 el fiscal de la causa requiere el sorteo, en el sistema pericial integral de la Función Judicial, de un perito que realice un estudio antropológico del procesado para establecer su origen étnico, sociocultural y pertenencia a una de las nacionalidades indígenas.

En este punto se podría profundizar sobre las violaciones de derechos del procesado y la debilidad de la defensa técnica en apelar a los derechos colectivos tanto del articulado Constitucional como de convenios y tratados internacionales de derechos humanos ${ }^{48}$ de los cuales el Ecuador es signatario; principalmente en cuanto a la medida cautelar de prisión preventiva que llevó a que el procesado permaneciera 20 días detenido, y que, una vez revisada en la audiencia, fue reemplazada por presentarse cada 5 días ante el fiscal que tramita la causa y la prohibición de salir del país. Es preciso exponer que K. Santi vive a dos horas de viaje de la ciudad donde fue procesado, por lo que el traslado cada 5 días requirió de tiempo y recursos económicos afectando a sus limitados ingresos.

El 20 de abril de 2017 se realiza la audiencia de juzgamiento, en la cual las consideraciones expuestas en la sentencia identifica como "Hecho dañoso.-[...] el transpor-

46. Ecuador, Unidad Judicial Penal con Sede en el cantón Pastaza, "Sentencia", Juicio 16281-2017-00170 (blog), el 20 de abril de 2017.

47. Ibíd.

48. El país es signatario del "Convenio 169 de la OIT sobre pueblos indígenas y tribales en estados independientes" y la Declaración de Naciones Unidas sobre los derechos de los pueblos indígenas. En el Convenio 169 se desarrollan las consideraciones del sistema judicial en cuanto a las particularidades culturales de los pueblos indígenas; así como en varias sentencias de la Corte Constitucional, como la Sentencia n. ${ }^{\circ}$ 004-14-SCN-CC, entre otras. 
te de carne ahumada correspondiente a sajino y dos tortugas motelo"; 49 la "Individualización del Procesado.- [...] K. Santi", el "Tipo penal.- [...] Art. 247 inciso primero del C.O.I.P”; cumpliéndose los fundamentos legales en el desarrollo de la audiencia la Fiscalía emitió dictamen abstentivo fundamentado en "son especies que no están amenazadas, en el tipo penal está la excepción, el antropólogo ha logrado establecer que las especies tienen ya agujeros", ${ }^{50} \mathrm{y}$, al no encontrar que la infracción "supere el filtro de la tipicidad", procede a retirar los cargos.

En el presente caso, el transporte de las tortugas motelo constituía el principal argumento del Ministerio del Ambiente para proceder a la acusación en contra de K. Santi, pues se sustentaba en que dicha especie se encuentra en peligro de extinción, tal como lo señala la Lista Roja de los Reptiles del Ecuador y conforme a la norma técnica para la aplicación del artículo 256 del COIP. Sin embargo, la acción por la cual K. Santi transportaba las tortugas y la carne silvestre era en el marco de un ritual de intercambio, exponiendo así una limitación en el tipo penal, pues, si bien la excepción de la disposición considera la "cacería, la pesca o captura por subsistencia, las prácticas de medicina tradicional", no abordan los aspectos rituales y otros más profundos de la diversidad cultural amazónica.

\section{LA JUSTICIA EN UN ESTADO PLURINACIONAL CON GARANTISMO PENAL}

La Constitución del Ecuador se funda sobre varios principios, entre ellos los de plurinacionalidad e interculturalidad ${ }^{51}$ que exponen aún ciertas brechas que es preciso tratar a partir de análisis que integren las visiones culturales y de derechos. En este contexto de diversidad, uno de los limitantes para el ejercicio de los derechos de estas colectividades es el sistema de justicia, que no considera las formas culturales particulares de reproducción socioeconómica, generando conflictos por esta incomprensión mutua.

En virtud de lo anterior, es necesario hacer un ejercicio de aplicación de principios constitucionales en las diferentes instancias del Estado, sobre todo en el ámbito judicial. La diversidad cultural presente en el país así lo exige, ya que solo así se permite limitar los conflictos que se presentan por la ausencia de un espacio de debate que integre la visión de esa diversidad. Para el efecto, es preciso que el ámbito judicial

49. Ecuador, Unidad Judicial Penal con Sede en el cantón Pastaza, "Sentencia".

50. Ecuador, Unidad Judicial Penal con Sede en el cantón Pastaza.

51. Agustín Grijalva, "El Estado Plurinacional e Intercultural en la Constitución Ecuatoriana del 2008”, Revista Ecuador Debate (Centro Andino de Acción Popular), 75 (2008): 49-62. 
tenga una comprensión amplia, ya sea bajo la concepción planteada por Boaventura de Souza que denomina "hermenéutica diatópica", ${ }^{2}$ que identifica "los temas que son parte del conflicto y que deben ceder su posición de premisas de la argumentación para que puedan motivar al mismo, $[. .$.$] siempre y cuando tengan una igualdad de$ poder", ${ }^{53} \mathrm{o}$ del desarrollo de espacios dialógicos que permitan una relación igualitaria entre los actores judiciales y la diversidad cultural. ${ }^{54}$ Esto en un marco de conocimiento y comprensión de las otredades.

Como se mencionó en capítulos precedentes, en la Amazonía ecuatoriana las formas culturales particulares de reproducción chocan con la normativa existente, entre ellos los tipos penales ${ }^{55}$ del COIP, relacionado con delitos contra la flora y fauna. La tipificación, si bien exceptúa la cacería con fines de subsistencia y las prácticas de medicina tradicional, no considera actividades rituales y simbólicas, que son prácticas recurrentes en varios pueblos y nacionalidades indígenas.

El caso, tal cual ha sido descrito en el capítulo anterior, expone las prácticas de un Estado que tiene en la institucionalidad pública, en este caso el Ministerio de Ambiente, la instancia que pone en práctica su "poder punitivo", ${ }^{56}$ que, como desarrolla Zafaronni, inicialmente estaría a cargo del aparato policial, sin embargo, terminan siendo las instancias burocráticas quienes lo ejercen. ${ }^{57}$

Si bien la "principal función del derecho penal es la de limitar el poder punitivo del Estado", ${ }^{58}$ y es en esa dirección a donde apunta el garantismo penal, en el procesamiento de delitos contra la flora y fauna la acción estatal es contraria y llega a procesar a una población que realiza sus actividades en un marco estrictamente cultural.

El garantismo penal tiene sus bases en derechos humanos, ${ }^{59}$ sin embargo, en el ejercicio del control social ejercido por el Estado estos se ven disminuidos y superados por la actuación penal, y en el caso de estudio llegan a imponerse y a generar una

52. Boaventura de Sousa Santos, Refundación del Estado en América Latina. Perspectiva desde una epistemología del Sur (Quito: Abya-Yala, 2011).

53. Ibíd.

54. Roberto Gargarella, ed., Por una justicia dialógica. El poder judicial como promotor de la deliberación democrática (Buenos Aires: Siglo XXI, 2014).

55. De acuerdo a Encalada (2015), "la tipicidad es la correspondencia entre una conducta humana y la descripción del hecho punible previsto en la ley penal". Ver Pablo Encalada, Teoría constitucional del delito. Análisis aplicado al Código Orgánico Integral Penal (Quito: Corporación de Estudios y Publicaciones, 2015).

56. Eugenio Zaffaroni, Estructura básica del derecho penal (Buenos Aires: Ediar, 2009).

57. Siguiendo la premisa de Zaffaroni, sería importante identificar si en el desenvolvimiento de las prácticas por parte de los representantes de la institución ambiental pública se han desarrollado estereotipos o estigmas en relación con el tipo de delito que estamos analizando.

58. Encalada, Teoría constitucional del delito, 6.

59. Ávila Santamaría, La (in)justicia penal en la democracia constitucional de derechos. 
situación de choque cultural.$^{60}$ Además expone la imposición de una estructura unicultural estatal que sigue reproduciendo las prácticas colonialistas que dan un dominio de la cultura oficial sobre la diversidad cultural.$^{61}$ El punto al que queremos llegar es a evidenciar la existencia de varios tipos de incompatibilidades, relacionadas no solo con lo jurídico conceptual, sino también con las particularidades en cuanto a percepciones respecto a bien jurídico protegido. De la misma forma, para los efectos jurídicos de acciones u omisiones individuales de individuos de pueblos y nacionalidades indígenas relacionadas con prácticas culturales particulares, e incluso de enfoque, que confrontan las visiones ius naturalistas y ius positivistas.

Como se mencionó, la investigación en materia penal se ha concentrado en el fenómeno jurídico como instrumento de control social que rige en un momento y en un espacio determinado, en el que la dogmática jurídica ha prevalecido incluso sobre las líneas de investigación (formalista-positivista). ${ }^{62}$ Por ello se impone la interpretación lógico sistémica del derecho en la que prima el principio de imputación, relacionado con lo dogmático, y no el de causalidad, cercano a lo sociológico y criminológico, y por ello en el presente caso el análisis se concentra en las conductas humanas de una cultura particular, que en el derecho positivo se encuentran tipificadas.

En relación a la visión occidental sobre el delito, Román ${ }^{63}$ plantea que este se explica desde lo formal, como una conducta contraria al ordenamiento jurídico, y desde la material, en cuanto un comportamiento que afecta a bienes jurídicos; ambas concepciones son establecidas en espacios legislativos donde prevalece una visión unicultural. Ante esto, el derecho penal tiene como objetivo "regular conductas humanas que puedan afectar bienes jurídicos penales que se consideran fundamentales para la sociedad", ${ }^{64} \mathrm{y}$ estos bienes jurídicos son justamente establecidos en procesos legislativos en los que prima una visión occidental, y donde existe una brecha en el ejercicio de la interculturalidad. Lo anterior se desprende de las visiones positivistas y neopositivistas en las que el objeto de análisis del derecho es el orden jurídico, la norma en su contenido dispositivo abstracto, cuyo fin es la determinación del contenido normativo del orden jurídico, pero limitado al positivismo.

En el análisis no discutimos lo pertinente de la tipificación en la que una sociedad establece los delitos, pues a partir de ello se da el principio de legalidad a las conduc-

60. Rodolfo Stavenhagen, "Derechos humanos y ciudadanía multicultural: los pueblos indígenas", en Demócratas, liberales y republicanos (Ciudad de México: El Colegio de México, 2000), 79-89.

61. Walsh, Interculturalidad, Estado.

62. Hans Kelsen, Teoría pura del derecho (Madrid: Trotta, 2011).

63. Román, Interculturalidad.

64. Ibíd., 65-6. 
tas punibles que controla acciones que puedan ir contra la sociedad. ${ }^{65}$ Se busca exponer las brechas en el desarrollo de un Estado intercultural en el ámbito de la justicia. El poder legislativo, encargado de dictar las leyes, no realiza un ejercicio pluralista de considerar la diversidad cultural del país y emite normativas que encasillan a las actuaciones individuales en estas tipificaciones con un desconocimiento de las particularidades culturales.

La premisa de que la ley penal protege bienes jurídicos implica que dicha protección, a través de tipos penales, debe considerar derechos. ${ }^{66} \mathrm{Se}$ dan las condiciones para que las garantías penales establezcan un límite al Estado y su capacidad punitiva, y permitan dinámicas sociales que se sostengan en principios de convivencia, ejerciéndose a través de normas acordadas de manera amplia. También es preciso que la concepción de bienes jurídicos se analice en el marco de la plurinacionalidad e incorpore las diversas visiones y concepciones filosóficas propias de las culturas de los pueblos y nacionalidades originarias del Ecuador. Con esta base conceptual, e incorporando las concepciones pluriculturales sobre bienes jurídicos, se podrá desarrollar una tipificación que responda a las formas culturales particulares. Justamente el pluralismo jurídico, que disputa al derecho positivo la hegemonía o predominio, permite abrir el abanico de análisis y de consideraciones que integren visiones desde la particularidad cultural, más aún cuando este es alimentado por el principio de interculturalidad, y que busca la comprensión, entendimiento e integración de la diversidad. ${ }^{67}$

En lo particular, el tipo penal Delitos contra la flora y fauna silvestre se encuentra en el capítulo cuarto del COIP, Delitos contra el ambiente y la naturaleza o Pachamama, y regula los actos, en este caso cacería, pesca, captura, recolección, extracción, tenencia, transporte, trafico, beneficio, permuto, comercialización; exceptuando la cacería, pesca o captura por subsistencia, las prácticas de medicina tradicional, el uso y consumo doméstico. Sin embargo, dichas excepciones deben ser coordinadas con la autoridad ambiental nacional, esto es el Ministerio del Ambiente. Adicionalmente, la "Sección Cuarta, disposiciones comunes" establece las definiciones y normas de la

65. Francisco Muñoz Conde, Derecho penal y control social (Bogotá: Temis, 2004).

66. Walsh, Interculturalidad, Estado.

67. Boaventura de Sousa Santos, "Pluralismo jurídico y jurisdicción especial indígena", en Del olvido surgimos para traer nuevas esperanzas. La jurisdiccion especial indígena, ed. VV. AA. (Bogotá: Ministerio de Justicia y Derecho / Consejo Regional Indígena del Cauca / Ministerio del Interior / Direción General de Asuntos Indígenas, 1997); Guillermo Fernández-Maldonado y Lieselotte Viaene, Viviendo la justicia: pluralismo jurídico y justicia indígena en Ecuador (Quito: Oficina del Alto Comisionado de Naciones Unidas para los Derechos Humanos / Ministerio Coordinador de Patrimonio, 2012); Asier Martínez de Bringas, "Los sistemas normativos indígenas en el marco del pluralismo jurídico. Un análisis desde los derechos indígenas", UNED. Revista de Derecho Político 86 (abril de 2013): 411-44; Luhmann, Sistema jurídico. 
autoridad ambiental nacional que se detallan en la "Norma técnica para la aplicación del artículo 256 del Código Orgánico Integral Penal (COIP)". ${ }^{68}$

Al existir el tipo penal en la legislación nacional, la conducta -cacería- realizada por la población kichwa del Curaray es punible, pues esta está determinada como delito, ${ }^{69} \mathrm{y}$, dado que las actuaciones exceptuadas no se encuentran coordinadas con la autoridad ambiental, se convierte en una acción típica. En este contexto queda también en evidencia esa subordinación de las acciones enmarcadas en prácticas culturales y las limitaciones para el reconocimiento de las autoridades propias de los pueblos y nacionalidades indígenas, exponiendo nuevamente esa falta de reconocimiento de la diversidad cultural del país.

Por lo anterior, propugnar el reemplazo de la normativa vigente, en el derecho positivo, por no satisfacer el contexto plurinacional, es necesario, para lo cual se hace preciso, como señala Courtis, "la investigación de lege ferenda" "70 a fin de criticar la solución normativa que se encuentra vigente para la regulación de acciones u omisiones, buscando su reemplazo por otra norma que considere justamente las particularidades de la diversidad cultural presente en el país.

En el estudio de caso, a los ojos de la justicia ordinaria, la conducta punible se desarrolla en varios momentos, pese a ser la cacería parte de un tiempo ritual y festivo, y la tenencia y transporte posterior a un ritual de entrega de regalos y obsequios, en el que, aparte del objeto material, existe un intercambio simbólico. El acto de cacería materializa ya la acción punible y lleva implícita la voluntad del sujeto de realizarla, justamente en el marco ritual anteriormente descrito en el que se juegan elementos culturales como valor, reconocimiento social, prestigio, entre otros. La tenencia y el transporte, en cambio, son parte de la aceptación de los obsequios en un contexto de ritualidad que establece y reafirma alianzas que, a su vez, fortalece y revitaliza el orden social, el ethos y la identidad étnica. ${ }^{71}$

Ahora, ¿cuál fue la finalidad del acto? Para la comunidad y sus miembros es parte de unas prácticas enmarcadas en la cultura, un espacio de ritualidad donde la acción está vinculada a la vivencia del símbolo ${ }^{72}$ y, por tanto, la voluntad es distinta a la establecida en la legislación: es una voluntad que no merece el reproche penal, perdiendo así el carácter punible.

68. Ecuador, Ministerio del Ambiente, Acuerdo Ministerial 084, Registro Oficial 598, 30 de septiembre de 2008.

69. Eugenio Zaffaroni, Manual de Derecho Penal (Buenos Aires: Ediar, 2007).

70. Courtis, "El juego", 112.

71. Roberto Narváez, "Peritaje para establecer el origen étnico de Santi Aguinda Klever Rafael, dentro del Expediente Fiscal n. ${ }^{\circ}$ 160101817030149(2017-00170)" (Peritaje antropológico, 2017).

72. Marco Vinicio Rueda, Mitología (Quito: Pontificia Universidad Católica del Ecuador, 1993). 
La cacería y el posterior transporte no corresponden a una acción antijurídica, pues culturalmente este tipo de acciones son aceptables al ser parte de la forma de vida tradicional y responde a tiempos festivos que exhiben una ritualidad. Así mismo, la concepción respecto a bien jurídico es diferente, ya que la forma de relacionamiento con el medio circundante es diferente al enmarcarse en la cultura tradicional. La acción es un concepto abordado de distintas maneras por la dogmática penal; sin embargo, en todas ellas la remiten al entorno social del que se desprende dicha acción, ${ }^{73}$ siendo el concepto social de acción, ${ }^{74}$ en el caso de Ecuador, distinto al de la diversidad cultural y por tanto va a variar el sentido de cada una de las colectividades culturales, generando un conflicto de comprensión entre las nacionalidades y pueblos originarios y la sociedad mayoritaria, replicando una vez el choque que se presenta en los Estados multiculturales. ${ }^{75}$

Por lo anterior, se identifica que en el derecho penal la atención principal es la ruptura del orden social, ${ }^{76}$ así como el vínculo de estas acciones con la conducta ética social del individuo. Esto se hace sin considerar que está sujeto a la dinámica de la pluralidad cultural, con aspectos particulares a cada una de ellas, por lo que la concepción de delito, como acción u omisión típica, antijurídica y culpable no son suficientes.

En el presente caso el sujeto activo del tipo penal analizado es K. Santi, con una diferencia cultural marcada en relación con la sociedad nacional. ${ }^{77}$ Los objetos materiales encontrados en el vehículo, y que fueron retenidos, son el objeto material de la infracción que están dentro de los detalles del tipo penal que señala "flora y fauna silvestre terrestre, marina o acuática, de especies amenazadas, en peligro de extinción y migratorias listadas a nivel nacional o consten en instrumentos o tratados internacionales". ${ }^{78}$

De esta manera, una situación culturalmente cotidiana tiene una ruptura el momento en que actores del Estado intervienen y ejercen una acción punitiva, con una reacción que lleva a mover una institucionalidad pública, representada por el Ministerio

73. Muñoz Conde, Derecho penal.

74. Claus Roxin, Derecho penal. Parte general (Madrid: Civitas, 1997).

75. Will Kymlicka, Ciudadanía Multicultural. Una teoría liberal de los derechos de las minorías (Barcelona: Paidós, 1996).

76. Muñoz Conde, Derecho penal.

77. Justamente en esa sociedad nacional, con un carácter unicultural que excluye y margina la diversidad cultural, e impone con las estructuras del Estado las dinámicas en las formas de relacionamiento al interior del mismo, la institucionalidad reproduce formas de colonialismo. Ver Boaventura de Sousa Santos, "Las paradojas de nuestro tiempo y la plurinacionalidad", en Plurinacionalidad: democracia en la diversidad (Quito: Abya-Yala, 2009), 24-5; Díaz Polanco, "Etnia"; Díaz Polanco, Elogio de la diversidad; Walsh, Interculturalidad, Estado.

78. Ecuador, COIP, art. 247. 
del Ambiente, en contra de un individuo y su familia, pues, si bien solamente K. Santi fue detenido, su familia (esposa y 3 menores de edad) se ve obligada a trasladarse a una jurisdicción lejana a su residencia ${ }^{79}$ sometiéndoles a una confrontación con un aparato judicial con dinámicas de las que existe una limitada comprensión en general de individuos de pueblos y nacionalidades indígenas, y también una distinción, en los administradores de justicia, "en el ejercicio de administración de justicia, entre quienes están dentro y quienes están fuera del orden social", ${ }^{80}$ que en términos de Encalada se desarrollan como "microagresiones racistas" ${ }^{81}$ en las dependencias de justicia ordinaria.

Así, el caso expone una condición de vulneración de derechos hacia la diversidad cultural, pues la intervención del Ministerio del Ambiente exhibe una actuación persecutora que, junto al sistema de justicia, cierra un cerco punitivo, en el que la existencia de un tipo penal con una limitada visión intercultural permite el procesamiento judicial. Por una parte, el Ministerio del Ambiente como autoridad ambiental interviene en la primera parte del proceso, "persiguiendo el delito",;2 a continuación, el procesamiento en el sistema de justicia utiliza la prisión preventiva como un instrumento punitivo, siendo esta de último ratio, con resultado de prisión por una práctica cultural. Luego el proceso judicial identifica, mediante una pericia de carácter antropológico, la existencia de un contexto cultural particular y, a partir de ello, en la audiencia de juzgamiento y con la incorporación plena de la prueba con la presentación oral de la pericia, la fiscalía considera la prueba como un elemento fundamental para identificar el conflicto existente y dar una valoración a esa información cultural inhibiéndose de acusar. Al no existir acusación, el caso se cierra.

Este caso expresa un dilema en el ejercicio de la interculturalidad, e identifica que el conflicto se inicia con la existencia de un tipo penal asentado en una base monocultural, y, por tanto, sancionador de ciertas prácticas culturales tradicionales. Si bien en el caso de un procesamiento judicial se podría identificar un error de tipo invencible, dado que la actividad de cacería y el transporte de este tipo de elementos en la concepción kichwa no es considerada una conducta que afecte un bien jurídico,

79. La ciudad del Puyo, capital de la provincia del Pastaza, que es la jurisdicción en donde se dio la detención, se encuentra aproximadamente a 3 horas de Ahuano.

80. Sofía Tiscornia, Entre el Imperio del Estado de Policía y los límites del Derecho (Buenos Aires: Informe anual Eudeba, 1999).

81. Karla Encalada Falconí, Rusticidad, indígenas en la cárcel y racismo legal. Una etnografía del sistema de justicia estatal y las élites en Riobamba, Ecuador (Buenos Aires: Antropofagia, 2016), 57.

82. Foucault, Vigilar y castigar; Eugenio Zaffaroni, La palabra de los muertos: conferencias de criminología cautelar (Quito: El Siglo, 2018). 
no existiendo dolo, dejando a este tipo de conducta como atípica. ${ }^{83}$ Pero se abre la posibilidad de un procesamiento judicial y por tanto de una afectación a los derechos y a las garantías de la diversidad cultural, exhibiendo una incompatibilidad de la norma con el ejercicio intercultural, tal como se aprecia en este caso en que el procesamiento involucró la privación de la libertad, con un impacto sobre el individuo procesado y su núcleo familiar.

De esta manera, encontramos que la cacería y el transporte de fauna no constituyen una conducta antijurídica en la cultura kichwa, por cuanto estas actividades se vinculan con un contexto de subsistencia y ritualidad, siendo parte de sus prácticas tradicionales, con una visión del mundo diferente, con principios y valores igualmente disímiles a los que priman en el resto de sociedad nacional. Así, en el ámbito cultural particular la práctica tradicional no está cargada de culpa pues no hay una acción antijurídica, al no existir reprochabilidad.

Según ell COIP, la culpabilidad, en la parte dogmática, se encuentra ligada a la responsabilidad penal y, por ende, a la responsabilidad del actor por la acción antijurídica; en este caso, dicha antijuricidad no existe porque la visión cultural kichwa no identifica una afectación a bien jurídico y, por tanto, anula una posible relación entre culpa y responsabilidad penal. Considerando la lógica del garantismo, la acción punitiva del Estado a través del derecho penal debe ser subsidiario, ${ }^{84} \mathrm{o}$ cuando las conductas humanas afecten bienes jurídicos, siendo este aspecto el sustancial, ya que la construcción de bienes jurídicos se enmarca en concepciones culturales, y estas no son homogéneas.

Con la argumentación anterior queremos destacar que, en el desarrollo de la teoría del delito, como filtro para la acción punitiva del Estado el error de tipo invencible e incluso el error de prohibición son recursos del derecho penal que no elimina ese limitado ejercicio de interculturalidad. Este debe darse con la emisión misma de la normativa, que es el fondo al que queremos llegar con este análisis, pues, mientras no se abra la posibilidad de una interpretación legal más plural, la acción judicial va a seguir incrementando el procesamiento de individuos de pueblos y nacionalidades indígenas por hechos que puedan estar involucrados con prácticas relacionadas con lo cultural, dejando en ciernes el ejercicio real del principio de interculturalidad, evidenciando una falta de seguridad jurídica para la diversidad cultural, ya que desde la justicia ordinaria se hace un procesamiento judicial de actividades culturales, dada la nula comprensión intercultural en la emisión de la norma.

83. Santiago Mir Puig, Derecho Penal. Parte General (Barcelona: Reppertor, 2015), 280.

84. Román, Interculturalidad. 


\section{CONCLUSIONES}

El desconocimiento de la norma constituye un factor repetitivo en el genérico de miembros de pueblos y nacionalidades originarias, y se remite a una relación inequitativa en la cual el Estado no ha prestado de manera adecuada los servicios públicos en los pequeños poblados amazónicos, y menos aún en las comunidades indígenas; por lo que el desconocimiento de la ley persiste en el territorio amazónico. Sin embargo, el desconocimiento no es el argumento importante en cuanto al procesamiento judicial, sino, principalmente, la compatibilidad entre las acciones normadas y las que son tradicionales en pueblos y nacionalidades originarias.

El tipo penal establece las acciones penadas; sin embargo, y en el marco de un Estado plurinacional, el limitante se encuentra en que el desarrollo de la norma mantiene aún una visión unicultural, por lo que es preciso que esta se desarrolle con la consideración de diversidad cultural y con una base fundamentalmente intercultural, permitiendo así que las particularidades culturales sean consideradas cuando se emitan las normas legales, para que, de esta manera, ciertas prácticas culturales no lleguen a chocar y no se limiten o afecten derechos.

Existe una brecha en el ejercicio de la interculturalidad. Se identifica una acción punitiva en la actuación institucional e interinstitucional del Estado, en la que el Ministerio de Ambiente se convierte en un actor de persecución del delito, concentrando su atención en un segmento poblacional incluso bajo consideraciones estigmatizantes. Se interviene en prácticas culturales con un desconocimiento de sus elementos y particularidades de carácter simbólico, rompiendo los preceptos del procesamiento penal como última ratio, y, más aún, el de privación de libertad.

La carne silvestre por la que fue procesado K. Santi tenía como finalidad el autoconsumo, y fue un regalo proporcionado por sus familiares, después de la celebración de San José, en Curaray, donde la práctica tradicional es el ritual de cacería que se comparte en una gran fiesta, homenajeando a la abundancia de los recursos de la selva y ofrendando los productos a la tierra y a los habitantes de la población. El regalo de las tortugas debe ser comprendido como parte de un ritual que establece lazos de intercambio y de acuerdos mutuos; adicionalmente, la presencia de animales silvestres en espacios domésticos es una forma de reproducir la abundancia de la selva en los mismos.

La conducta por la cual fue procesado K. Santi es una conducta prohibida de acuerdo a la legislación vigente en la que existe preponderancia de la cultura mestiza, incluso impositiva, que no permite una integración de la diversidad cultural en la estructura de ordenamiento del Estado, tanto en la formulación de esa legislación como en el cumplimiento de la misma. Así, el tipo penal no ha sido comprendido no solo porque no haya sido socializado por el Estado, sino porque su comprensión tiene un límite en 
la particularidad cultural, presentándose un choque entre dos culturas que expone una subordinación; es decir, la prevalencia de una sobre la otra.

En el caso analizado se evidencia una brecha en el ejercicio de la justicia en un Estado plurinacional e intercultural, que nos lleva a plantear la necesidad de un espacio abierto e interactivo, del que participen la institucionalidad judicial del Estado y los representantes de las nacionalidades y pueblos originarios, con el fin de establecer líneas de trabajo tendientes a armonizar la legislación nacional, teniendo las consideraciones pertinentes para el ejercicio pleno de los derechos y de los principios constitucionales de plurinacionalidad; es decir, reconocimiento a la diversidad y sus formas e instituciones propias. Finalmente, el enfoque de interculturalidad debe realizarse en espacios donde confluyan las culturas en un marco de respeto e igualdad.

\section{BIBLIOGRAFÍA}

Ávila, Luis. "Barreras ideológicas para la valoración judicial de los peritajes antropológicos". Revista Crítica Jurídica (Instituto de Ciencias Jurídicas de la Universidad Autónoma de México), 31 (2011): 15-37.

Ávila Santamaría, Ramiro. “¿Debe aprender el derecho penal estatal de la justicia indígena?”. En Justicia indígena, plurinacionalidad e interculturalidad en Ecuador, editado por Boaventura de Sousa Santos y Agustín Grijalva, 279-304. Quito: Abya-Yala, 2013.

—. La (in)justicia penal en la democracia constitucional de derechos: una mirada desde el garantismo penal. Quito: Ediciones Legales, EDLE / Universidad Andina Simón Bolívar, 2013.

Benavente, Hesbert. La aplicación de la teoría del caso y la teoría del delito en el proceso penal acusatorio. Barcelona: Bosch Editor, 2011.

Benítez, Lilian, y Alicia Garcés. Culturas ecuatorianas. Ayer y hoy. Quito: Abya-Yala, 1992.

Bourdieu, Pierre, y Gunther Teubner. La fuerza del derecho. Bogotá: Uniandes, 2000.

Clavero, Bartolomé. Geografia jurídica de América Latina. Pueblos indígenas y constituciones mestizas. Ciudad de México: Siglo XXI, 2008.

Courtis, Christian. "El juego de los juristas: Ensayo de caracterización de la investigación dogmática". En Observar la ley: ensayos sobre metodologías de la investigación jurídica, editado por Christian Courtis y Manuel Atienza, 105-56. Madrid: Trotta, 2006.

De Sousa Santos, Boaventura. "Las paradojas de nuestro tiempo y la plurinacionalidad". En Plurinacionalidad: democracia en la diversidad, 24-5. Quito: Abya-Yala, 2009.

—. "Pluralismo jurídico y jurisdicción especial indígena". En Del olvido surgimos para traer nuevas esperanzas. La jurisdicción especial indígena, editado por VV. AA. Bogotá: Ministerio de Justicia y Derecho / Consejo Regional Indígena del Cauca / Ministerio del Interior / Direción General de Asuntos Indígenas, 1997. 
- Refundación del Estado en América Latina. Perspectiva desde una epistemología del Sur. Quito: Abya-Yala, 2011.

De Sousa Santos, Boaventura, y José Exeni Rodríguez. Justicia indígena, plurinacionalidad e interculturalidad en Bolivia. Vol. 27. La Paz: Abya-Yala / Fundación Rosa Luxemburgo, 2012.

Díaz Polanco, Héctor. Elogio de la diversidad. Globalización, multiculturalismo y etnofagia. Ciudad de México: Siglo XXI, 2006.

—. "Etnia, clase y cuestión nacional". Cuadernos Políticos 30 (octubre-diciembre 1981): 5365.

Ecuador. Código Orgánico Integral Penal. Registro Oficial Suplemento 180, 10 de febrero de 2014.

-. Constitución de la República del Ecuador. Registro Oficial 449, 20 de octubre de 2008.

—. Fiscalía de Pastaza. "Expediente fiscal”. Instrucción Fiscal 160101817030149 (blog), marzo de 2017.

—. Ministerio del Ambiente. Acuerdo Ministerial 084. Registro Oficial 598, 30 de septiembre de 2008.

-. Unidad Judicial Penal con Sede en el cantón Pastaza. "Sentencia”. Juicio 16281-201700170 (blog), 20 de abril de 2017.

Encalada Falconí, Karla. Rusticidad, indígenas en la cárcel y racismo legal. Una etnografía del sistema de justicia estatal y las élites en Riobamba, Ecuador. Buenos Aires: Antropofagia, 2016.

Encalada, Pablo. Teoría Constitucional del Delito. Análisis aplicado al Código Orgánico Integral Penal. Quito: Corporación de Estudios y Publicaciones, 2015.

Fernández, Gonzalo. Bien jurídico y sistema del delito. Buenos Aires: Julio César, Editor, 2004.

Fernández-Maldonado, Guillermo, y Lieselotte Viaene. Viviendo la justicia: Pluralismo jurídico y justicia indígena en Ecuador. Quito: Oficina del Alto Comisionado de Naciones Unidas para los Derechos Humanos / Ministerio Coordinador de Patrimonio, 2012.

Ferrajoli, Luigi. Derecho y razón. Teoría del Garantismo Penal. Madrid: Trotta, 2005.

—. Derechos y garantías: la ley del más débil. Madrid: Trotta, 2005.

Foucault, Michel. El pensamiento del afuera. Valencia: Pre-textos, 2000.

—. La sociedad punitiva. Buenos Aires: Fondo de Cultura Económica, 2016.

—. Vigilar y castigar. Buenos Aires: Siglo XXI, 1976.

Gargarella, Roberto, ed. Por una justicia dialógica. El poder judicial como promotor de la deliberación democrática. Buenos Aires: Siglo XXI, 2014.

Grijalva, Agustín. "Conclusiones de todos los estudios: Experiencias diversas y convergentes de la justicia indígena en Ecuador". En Justicia indígena, plurinacionalidad e interculturalidad en Ecuador, editado por Boaventura de Sousa Santos y Agustín Grijalva, 551-78. Quito: Abya-Yala, 2013. 
—. "El Estado Plurinacional e Intercultural en la Constitución Ecuatoriana del 2008". Revista Ecuador Debate, Centro Andino de Acción Popular, 75 (2008): 49-62.

Hudelson, John Edwin. La cultura quichua de transición. Su expansión y desarrollo en el Alto Amazonas. Quito: Museo Antropológico del Banco Central / Abya-Yala, 1987.

Kelsen, Hans. Teoría pura del derecho. Madrid: Trotta, 2011.

Kymlicka, Will. Ciudadanía Multicultural. Una teoría liberal de los derechos de las minorías. Barcelona: Paidós, 1996.

—. "Pensar el multiculturalismo". Íconos. Revista de Ciencias Sociales (FLACSO Ecuador), n. ${ }^{\circ} 10$ (abril 2001): 118-29.

Loperena, Christopher, Rosalva Aída Hernández Castillo y Mariana Mora. "Los retos del peritaje cultural: el antropólogo como perito en la defensa de los derechos indígenas". Desacatos; Tlalpan, n. ${ }^{\circ} 57$ (2018): 8-19.

Luhmann, Niklas. Sistema jurídico y dogmática jurídica. Madrid: CEC, 1983.

Madrid, Andrea. "Entre killas y pifanos: desde la memoria social de los pueblos kichwas del Cuyabeno. Estudio de caso en la comunidad de Zancudo Cocha". Antropología Cuadernos de Investigación 12 (2013).

Martínez de Bringas, Asier. "Los sistemas normativos indígenas en el marco del pluralismo jurídico. Un análisis desde los derechos indígenas". UNED. Revista de Derecho Político 86 (abril de 2013): 411-44.

Mir Puig, Santiago. Derecho Penal. Parte General. Barcelona: Reppertor, 2015.

Moya, Alba. Ethnos. Atlas mitológico de los pueblos indígenas del Ecuador. Quito: Proyecto de Educación Bilingüe Intercultural / Ministerio de Educación y Cultura del Ecuador / GTZ, 1999.

Muñoz Conde, Francisco. Derecho penal y control social. Bogotá: Temis, 2004.

Muratorio, Blanca. Rucuyaya Alonso y la historia social y económica del Alto Napo, 18501950. Vol. 68. Quito: Abya-Yala, 1987.

Narváez, Roberto. "Estudio afectación a la seguridad y soberanía alimentaria de Sarayaku”, sin publicar, 2010.

—. "Peritaje para establecer el origen étnico de Santi Aguinda Klever Rafael, dentro del Expediente Fiscal Nro. 160101817030149(2017-00170)”. Peritaje antropológico, 2017.

—. “UUn ejercicio de aplicación de la justicia intercultural? El caso waorani en la Amazonía Ecuatoriana". Revista Antropologías del Sur, año 3, n. ${ }^{\circ} 6$ (2016): 163-79.

Nils, Christie. Una sensata cantidad de delito. Buenos Aires: Ediciones del Puerto, 2004.

Reeve, Mary Elizabeth. Los quichuas del Curaray: el proceso de formación de la identidad. Quito: Banco Central del Ecuador / Abya-Yala, 1988.

Román, Álvaro. Interculturalidad, libertad y pena. Quito: Universidad Andina Simón Bolívar / Corporación Editora Nacional, 2015.

Roxin, Claus. Derecho penal. Parte General. Madrid: Civitas, 1997. 
Rueda, Marco Vinicio. "Encuentros del cristianismo español con las religiones precolombinas". En Cosmos, hombre y sacralidad, editado por Marco Vinicio Rueda y Segundo Moreno, 267-304. Quito: Departamento de Antropología de la Universidad Católica, 1995.

—.Mitología. Quito: Pontificia Universidad Católica del Ecuador, 1993.

Sierra, María Teresa. "Mujeres indígenas, justicia y derechos: los retos de una justicia intercultural". Iconos, n. ${ }^{\circ} 31$ (2008): 15-26.

Stavenhagen, Rodolfo. "Conflictos étnicos y estado: Conclusiones de un análisis comparativo nacional”. Estudios Sociológicos (El Colegio de México) XIX, n. ${ }^{o} 1$ (enero-abril 2001): $3-25$.

- "Derechos humanos y ciudadanía multicultural: los pueblos indígenas". En Demócratas, Liberales y Repúblicanos, 79-89. Ciudad de México: El Colegio de México, 2000.

Tiscornia, Sofía. Entre el Imperio del Estado de Policía y los límites del Derecho. Buenos Aires: Informe anual Eudeba, 1999.

Walsh, Catherine. Interculturalidad, Estado, sociedad. Luchas (de)coloniales de nuestra época. Quito: Universidad Andina Simón Bolívar / Abya-Yala, 2009.

Whitten, Norman E. "La Amazonía actual en la base de los andes: una confluencia étnica en la perspectiva ecológica, social e ideológica". En Amazonía ecuatoriana. La otra cara del progreso, 13-60. Quito: Abya-Yala, 1989.

Zaffaroni, Eugenio. Estructura básica del derecho penal. Buenos Aires: Ediar, 2009.

- La palabra de los muertos: Conferencias de criminología cautelar. Quito: El Siglo, 2018.

—. Manual de Derecho Penal. Buenos Aires: Ediar, 2007. 